\title{
Um modelo de formação e sua aplicação em educação continuada
}

\author{
An education model and its application for continuing education
}

Edna Maria Querido de Oliveira Chamon ${ }^{1}$

\begin{abstract}
Resumo
Tendo em vista a importância e atualidade dos trabalhos sobre formação continuada de professores, realizou-se uma pesquisa junto a 189 professores da rede estadual de ensino do estado de São Paulo para avaliar uma formação que eles cursavam. 0 quadro teórico que apoiou a análise baseou-se nas características conceituais, psicológicas e profissionais que orientam o desenho de uma formação. A pesquisa mostrou que a formação proposta apresentou componentes dos três pólos do modelo teórico, com dominância variável entre eles. Em particular, o trabalho de pesquisa de conclusão de curso, representado pela monografia que os professores desenvolveram sobre tema educacional, foi um dos principais elementos aglutinadores desses três pólos. Foi possível, também, observar a adequação do modelo para a análise de uma formação continuada.
\end{abstract}

Palavras-chave: Formação Continuada; Modelo de Formação; Profissão Docente

\section{Abstract}

Considering the relevance of works about continuing teacher education, we have conducted a research with 189 teachers enrolled in an education program to evaluate it. The theoretical framework supporting our analysis is based on the conceptual, psychological, and professional characteristics that guide the education design. The research showed the presence of these three components with variable levels of domination. Particularly, the research work represented by the thesis developed by the students during the education program was one of the main aggregation points of these components. It was possible to observe the model adequacy to a continuing education analysis.

Keywords: Continuing Teacher Education; Education Model; Teaching Profession

1 Departamento de Economia, Contabilidade e Administração da Universidade de Taubaté UNITAU (Taubaté/Brasil). edna_chamon@directnet.com.br. 


\section{INTRODUÇÃO}

Toda formação continuada de professores procura, em alguma medida, implementar dinâmicas de revitalização e aprofundamento de conhecimentos necessários à prática docente, além de buscar intervenções inovadoras no sistema educativo. Tais ideais, embora não excludentes, não são facilmente conciliáveis, dada a profusão e diversidade de interesses, objetivos e agentes envolvidos no processo (PARDAL; MARTINS, 2005).

Ainda assim, a complexidade real do processo de formação não nos impede de buscar compreendê-lo. De fato, inúmeras são as iniciativas de formação continuada de professores - oficinas, workshops, cursos de curta duração, seminários e palestras, grupos de estudo - que se apresentam no cotidiano do professor e que requerem a reflexão acadêmica.

Buscando contribuir para essa reflexão, apresentamos aqui um modelo analítico para o processo de formação continuada, juntamente com um exemplo de sua aplicação. O modelo, dito "triângulo da formação", foi proposto originalmente por Fabre (1994) para o quadro abstrato de uma formação geral e adaptado nesta pesquisa para situações específicas de formação de professores. Esse modelo alinha-se com outras proposições baseadas na classificação habermasiana das racionalidades ou interesses (HABERMAS, 1976; SILVA 2000), porém amplia a análise, caracterizando articulações possíveis entre elas.

Paralelamente ao modelo, apresenta-se a avaliação de uma formação continuada de professores, do ponto de vista dos formandos. Essa pesquisa - que emprega o triângulo da formação como guia de leitura - sugere o potencial do uso do modelo na avaliação de programas de formação.

\section{A FORMAÇão CONTINUAda}

Podemos entender a formação continuada como uma atividade seqüencial, que ocorre ao longo da carreira docente, após uma certificação profissional primeira, e que é oferecida àqueles que já possuem uma experiência de ensino (SILVA, 2000). Essa caracterização não implica necessariamente em uma formação prévia de nível universitário, uma vez que as antigas certificações obtidas em escolas normais permitiam aos formados o exercício do magistério. 
Esse tipo de formação nasceu das atividades de treinamento e aperfeiçoamento desenvolvidas nas décadas de 1940 a 1970, nas quais predominava o caráter compensatório, buscando-se, principalmente, corrigir lacunas da formação inicial (PIMENTEL, 2004). A partir da década de 1980, não apenas em função dos baixos resultados obtidos nesses programas de treinamento, mas também como um primeiro reflexo do processo de reestruturação produtiva que se anunciava no mundo capitalista, a formação continuada modificou-se, buscando introduzir, além de preocupações relativas aos conteúdos e às estratégias de ensinoaprendizagem, aquelas relativas aos saberes e competências dos professores (apenas como referência, The Reflective Practitioner, de Donald Schön, é de 1983).

$\mathrm{Na}$ realidade, a cada nova etapa de desenvolvimento social e econômico, definem-se novas necessidades do mercado de trabalho, levando ao aparecimento de novos projetos pedagógicos e novos perfis de professores identificados como adequados a essas necessidades (KUENZER, 1999; CASTRO, 2005). Assim, dentro da ótica do modelo de produção capitalista atual, características como flexibilidade, polivalência, capacidade de adaptação e de aprendizado são valorizadas, e terminam por se refletir nos projetos educacionais de governo, com impactos visíveis nos programas de formação de professores.

\section{MOdelos de fORMAÇÃo}

Um modelo é uma forma de representação abstrata de um fenômeno ou uma situação-objeto, cujas características e evolução se deseja descrever, prever ou explicar. Nesse sentido, um modelo é uma analogia, por utilizar um ente abstrato para inferir fatos sobre um outro ente, do mundo físico ou social.

Em nosso caso específico, modelos podem ser construídos para permitir o desenho, a avaliação ou a compreensão de uma formação. Nem sempre o modelo desenvolvido para uma dessas finalidades é adequado para todas as outras. Em particular, modelos empregados na compreensão de um processo formativo não têm, na maior parte das vezes, concretude suficiente para desenhar atividades de formação. Em se tratando de avaliação, o modelo deve ser capaz de

contrapor o desenho e a implementação com os objetivos estabelecidos nas propostas, examinando se os objetivos foram 
alcançados, se foram contempladas as condições sob as quais o professor atua, se foram observadas as condições apropriadas para o professor se capacitar e se os procedimentos para avaliar a utilidade do treinamento foram adequados (DUARTE, 2004, p. 157).

A literatura oferece várias propostas teóricas sobre prática de formação, sob a designação de modelos ou paradigmas. Um exemplo é o modelo desenvolvido por Simão, Caetano e Flores (2005), que apresenta cinco processos atuantes na mudança de professores: ação, colaboração, investigação, teoria e reflexão. Tais processos influenciam-se mutuamente por interações tensionais (tensões entre autonomia e interdependência, entre estruturação e flexibilidade etc.) e relacionam-se - isto é, afetam e são afetados - não apenas na dimensão pessoal (professores, alunos), mas também na dimensão contextual (escola, sistema educativo, comunidade). Embora pensado para processos de mudança mais gerais, o modelo colocase imediatamente para questões de formação continuada, como indicado pelas autoras.

Vários dos modelos existentes, incluindo o modelo do triângulo da formação, que será apresentado a seguir, podem ser descritos em termos das formas de racionalidade definidas por Habermas (1976), sendo centrados nas aquisições e na racionalidade instrumental, nas experiências e na racionalidade prática ou na análise e na racionalidade crítica. Organismos internacionais, como o Banco Mundial, têm privilegiado modelos de formação continuada centrados na aquisição de conteúdos (DUARTE, 2004), em detrimento da formação pedagógica dos professores, por exemplo.

\section{O triÂngulo da fOrmação}

Podemos agrupar os vários sentidos de formar sob três orientações:

1. transmitir conhecimentos, como em instruir;

2. modelar a personalidade inteira;

3. integrar o conhecimento à prática.

Essas três orientações indicam três lógicas de formação: a lógica didática (ou epistêmica) dos conteúdos e dos métodos; a lógica psicológica da evolução do indivíduo, e a lógica socioprofissional, da adaptação.

Essas lógicas estão presentes simultaneamente na realidade de uma formação, pois ela se dá num certo contexto, busca a transmissão de um 
saber e diz respeito a indivíduos que aprendem. Entretanto, a predominância de uma dessas lógicas define uma configuração particular de formação, profissional, psicossociológica ou epistêmica, dependendo de seu caráter de preparação para uma atividade, de desenvolvimento pessoal ou de construção do conhecimento. Essas formações articulam as três lógicas precedentes em níveis diferentes. Dessa forma, para cada configuração, teremos uma lógica dominante (que define a configuração), uma lógica dominada (utilizada para atingir o objetivo projetado) e uma lógica marginal (negligenciada na construção da formação, mas eventualmente presente na ação ou no produto). Por exemplo, uma formação profissional se constrói em torno de uma lógica socioprofissional, utilizando métodos e conteúdos. O desenvolvimento pessoal, que tem um papel marginal, está presente, embora talvez de maneira reduzida, no indivíduo formado.

O triângulo da formação mostrado a seguir, sintetiza as três configurações e suas relações com as lógicas de formação.

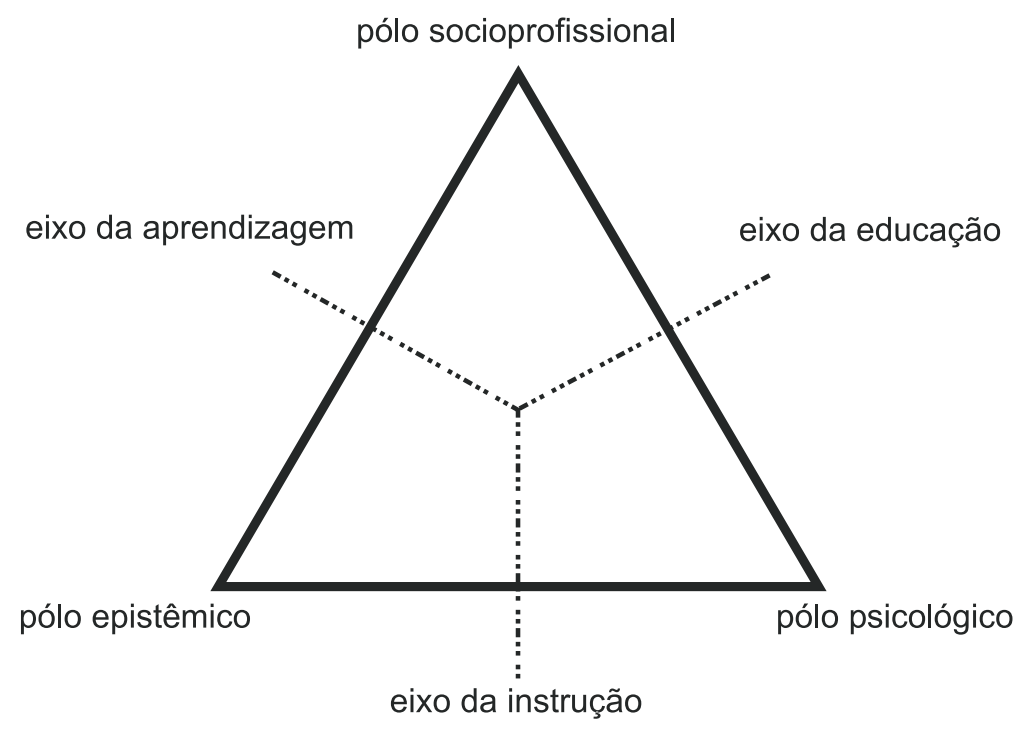

FIGURA 1 - Triângulo da formação

Fonte: FABRE, 1994, p. 26. 
Esse triângulo representa um modelo teórico de formação, cujo mérito principal é permitir que se pense a formação a partir de três elementos, suas articulações e suas dominâncias. Em particular, ele vai nos permitir analisar o processo de formação continuada dos professores. Esse modelo não se restringe a formações centradas no aspecto cognitivo (oferta de conteúdo e trabalho com a racionalidade dos professores), possibilitando levar em conta aspectos socioafetivos e culturais, cuja omissão está na raiz de muitas das críticas feitas a programas de formação (GATTI, 2003). Entretanto, é um modelo centrado na formação do indivíduo, deixando pouco espaço para considerações políticas ou de caráter mais coletivo.

O triângulo da formação deve ser visto como uma grade de leitura para o problema da formação. Ele permite pensar os programas de formação do ponto de vista de suas lógicas de construção, mostrando aquilo que foi privilegiado e o que foi omitido ou negligenciado. Assim, programas clássicos de formação, com foco no conteúdo a ser transmitido, estão centrados no pólo epistêmico do triângulo, com alguma articulação com os demais pólos, caracterizando uma problemática particular de formação. Já programas que buscam adaptação ao mercado - como muitos daqueles hoje financiados por organismos internacionais - estão claramente no pólo socioprofissional.

\section{AS LÓGICAS DA FORMAÇÃo}

$\mathrm{Na}$ base de toda formação podemos encontrar três pólos aos quais ela se relaciona: o sujeito, o conhecimento e a situação. Sempre presentes, ainda que em níveis de ativação diferentes, eles implicam três lógicas diferentes: psicológica, epistêmica e socioprofissional.

A lógica psicológica é aquela da evolução do indivíduo, da mudança qualitativa. A mudança individual é pensada em termos psíquicos, em termos de crise, ruptura e superação. É a lógica de formação que leva o indivíduo a se questionar, a modificar suas práticas e seus modos de relação com o mundo. Em física quântica, por exemplo, essa mudança qualitativa corresponde à passagem do determinismo à incerteza na descrição do mundo. Em psicologia do desenvolvimento, essa mudança corresponde à constatação de que o conhecimento é construído pela criança muito mais do que lhe é imposto externamente. Mais do que teorias científicas, novas maneiras de olhar a realidade são aprendidas. 
A lógica epistêmica é a dos conteúdos e métodos, é a lógica do conhecimento. É a formação em alguma coisa, a formação em pedagogia, por exemplo. A especificidade dessa lógica vem da relação entre o conhecimento e os problemas que lhe dão sentido. A dialética teoria/ prática, que é a dialética saber/saber-fazer, está na base de uma lógica de formação epistêmica.

Finalmente, a lógica socioprofissional é aquela da adaptação aos contextos culturais ou profissionais. É a lógica das primeiras definições de uma formação profissional, a formação para alguma coisa, tendo em vista uma adaptação mais ou menos ampla à sociedade. No sentido de uma adaptação ao posto de trabalho, essa lógica reflete o modelo taylorista, com seus princípios de decomposição de tarefas e separação dos trabalhos de concepção e execução. No sentido de reprodução social, de acordo com Bourdieu e Passeron (1970), ela reflete os objetivos políticoeconômicos da classe dominante. Modelos de formação centrados em competências ou que buscam a "certificação de professores" (FREITAS, 2003; DIAS; LOPES, 2003) colocam-se dentro dessa lógica socioprofissional.

\section{As PROBlemáticas da FORMAÇÃo}

A problemática da formação repousa na articulação das três lógicas analisadas anteriormente. Essa articulação se constrói em torno de uma lógica dominante e de uma lógica dominada, o que marginaliza a terceira lógica. Assim, uma modalidade de formação será definida por um problema fundamental de articulação entre dois pólos e será caracterizada pelos questionamentos do pólo negligenciado. Teremos, então, não apenas uma, mas três problemáticas possíveis, em função das combinações entre os pólos da formação (ALTET; FABRE, 1994):

- a problemática de articulação entre valor epistemológico e desenvolvimento pessoal;

- a problemática de articulação entre desenvolvimento pessoal e inserção socioprofissional; e

- a problemática de articulação entre valor epistemológico e interesse socioprofissional.

A formação continuada de professores se inscreve em cada uma dessas problemáticas, mas a cada vez ela adquire um sentido diferente. 
Ela pode representar a formação no sentido de transmissão de informações, de orientação científica (formação no sentido de instrução). É a abordagem tradicional do problema, defendida por vários pesquisadores (CARVALHO; SIMÕES, 2002), e baseia-se na idéia da ampla difusão do conhecimento como chave para o desenvolvimento futuro. Apóia-se freqüentemente no uso de novas tecnologias para a transmissão de informações ou competências. Trata-se, entretanto - e essa é sua limitação fundamental -, de uma estratégia proposta de forma vertical, onde a formação é vista como um produto, baseada em pacotes de treinamento.

Por outro lado, a formação continuada pode ser vista em um sentido mais amplo de reflexão e questionamento, próxima da formação no sentido de transformação da pessoa. É uma abordagem centrada no professor como sujeito, buscando a formação do professor reflexivo tanto em relação ao seu saber (teórico) como seu saber-fazer (prático). Sua limitação fundamental é não integrar o contexto sociopolítico mais amplo, não contemplando a escola e seus projetos, restringindo-se ao professor e sua atividade em sala de aula.

Finalmente, a formação continuada pode contemplar processos de adaptação socioprofissional, de caráter mais individual, ou de adaptação ao projeto da escola, de caráter mais coletivo. É a formação vista em seu aspecto de ensino. Essa abordagem procura preparar o professor para transformações institucionais. Normalmente associada à socialização profissional, com aspectos de carreira e integração ao grupo, essa visão tende a marginalizar transformações pessoais mais globais.

\section{A FORMAÇÃo CONTINUADA COMO UM EIXO DE INSTRUÇÃO}

O primeiro contexto onde a formação continuada pode se inscrever diz respeito à articulação entre um valor epistêmico e um valor formador de concepções do saber (articulação entre os pólos epistêmico e psicológico). Nessa ótica, a função da formação é modificar as relações entre o sujeito e o conhecimento: passa-se da transmissão do conhecimento por um formador a uma produção ativa desse conhecimento por parte do sujeito. Trata-se de construir uma nova representação do conhecimento como um processo de elaboração, em movimento, como construção inacabada. A atividade de pesquisa, que muitas vezes está associada à formação continuada (monografias de fim de curso, por exemplo), caracteriza muito bem essa problemática de formação. Essa 
atividade se exerce em dois níveis (BEILLEROT, apud ALTET; FABRE, 1994):

- o nível das condições mínimas da pesquisa: produção de novos conhecimentos (pólo epistêmico), método de investigação rigoroso e comunicação de resultados;

- o nível das características suplementares: dimensão crítica ou reflexiva (pólo psicológico), sistematização da coleta de dados e quadro teórico interpretativo.

É preciso observar, entretanto, que o conhecimento científico por si só não tem valor formador. A busca de conhecimento que comporta uma componente moral orientadora da ação é uma concepção grega, que não é mais corrente hoje em dia. O modelo de conhecimento atual, que tem suas raízes no século XII, com a criação da Universidade no Ocidente, é historicamente marcado por um duplo (e, num certo sentido, paradoxal) movimento: por um lado, a fragmentação do conhecimento, com sua organização em áreas, disciplinas e especialidades; por outro, a reunião desses "fragmentos" num espaço institucional comum - a Universidade numa tentativa de união de suas diversas e dispersas partes (DOMINGUES et al., 2001).

O conhecimento, assim, se caracteriza pela especialização e pela fragmentação - segundo Silva (2001), em 1994 havia 8.530 campos do conhecimento repertoriados e catalogados - pela mecanização do pensamento e por uma planificação do tipo econômica (MATOS, 2001), que são incompatíveis com a formação individual em sentido amplo. Assim, a formação continuada - dentro da problemática apresentada exige a articulação com o pólo psicológico. Não há, entretanto, a preocupação com aspectos sociais ou profissionais mais amplos.

\section{A FoRMAÇÃo CONTINUADA COMO UM EIXO DE EDUCAÇÃo}

Esta problemática diz respeito a uma transformação do sujeito buscando uma adaptação social, uma equilibração no sentido piagetiano. A formação continuada pode igualmente se inscrever nessa problemática de articulação entre desenvolvimento pessoal e adaptação socioprofissional, aproximando-se, nesse caso, de uma formação filosófica, na medida em que implica em uma atitude de questionamento, de investigação e de reflexão. O valor pedagógico da formação aqui é o do assombro e do abalo, do questionamento. A articulação com o pólo 
socioprofissional vem do questionamento de si mesmo, que faz parte de um movimento de construção identitária profissional. São importantes nessa formação o trabalho em equipe e as trocas entre os participantes. A transmissão de conhecimentos é menos importante aqui do que a reflexão sobre o saber e o saber-fazer do professor.

\section{A FORMAÇÃo CONTINUADA COMO UM EIXO DE APRENDIZAGEM}

O problema fundamental aqui é o da formação profissional: como uma formação pode ser ao mesmo tempo válida no plano epistemológico e útil no plano socioprofissional?

A idéia inicial é a de formar para funções precisas, ligadas às novas atividades que surgem com as mudanças na profissão ou na estrutura da instituição. Trata-se de um aprendizado para resolução de problemas práticos, que um quadro de conhecimentos teóricos mais amplo permite tratar. Não há, nesse caso, questionamento do indivíduo ou do sistema, buscando-se, ao contrário, uma adaptação entre o indivíduo e suas tarefas. Essas tarefas podem representar tanto a atividade quotidiana do indivíduo, para a qual ele se recicla, quanto uma evolução profissional dentro do sistema, para a qual ele se prepara, como ainda uma adaptação a um novo projeto institucional, do qual ele participa.

$\mathrm{Na}$ prática, uma formação continuada privilegiará uma dessas três problemáticas, mantendo, entretanto, ainda que marginalmente, perspectivas do pólo marginalizado. Os modos tradicionais de formação insistiram fundamentalmente nas problemáticas centradas no pólo epistêmico - que corresponde a uma lógica técnica - negligenciando a função crítico-reflexiva da escola. Essa função, entretanto, sempre esteve presente na atividade teórica acadêmica (os trabalhos de pesquisa ligados à educação) e, ainda que de forma dispersa e difusa, nas práticas docentes (devido ao espaço imediato de autonomia que o professor mantém em sala de aula).

\section{A Pesquisa}

O presente trabalho buscou avaliar o ponto de vista de um conjunto de professores sobre uma formação a eles oferecida. Tratava-se de docentes efetivos PEB I (Professor do Ensino Básico I) do estado de São Paulo, que possuíam formação em nível médio (Habilitação Magistério), aos quais foi proposto um "programa experimental de licenciatura plena [...] 
fornecendo diploma correspondente expedido pelas instituições de ensino superior contratadas para este fim" (PEC, 2001, p. 12).

A formação, denominada PEC - Programa de Educação Continuada - destinou-se a professores com, no mínimo, dez anos de docência e se desenvolveu em paralelo com o trabalho docente nas escolas de origem desses professores. O ensino era presencial, com apoio expressivo de mídias interativas, organizado na forma de módulos. Os CEFAMs (Centros Específicos de Formação e Aperfeiçoamento do Magistério) forneceram a infra-estrutura física e de comunicação (multimídia) para o desenvolvimento do programa.

Dentro da carga horária proposta havia 800 horas de reconhecimento do exercício profissional, incorporadas às atividades complementares. Como parte das atividades de estudos independentes e trabalhos de síntese, o aluno-professor desenvolveu uma monografia (TCC - Trabalho de Conclusão de Curso) sobre algum tema educacional de seu interesse, sob supervisão de um orientador acadêmico, nos moldes exigidos pela Instituição de Ensino Superior à qual o grupo do aluno-professor estivesse associado.

A coleta de dados foi estruturada a partir de um questionário contendo questões fechadas, sociodemográficas, para caracterização da amostra; questões avaliativas da formação e questões relativas à profissão docente e à atividade do professor. Uma amostra de conveniência, representada pelos alunos-professores que seguiam a formação foi considerada para essa pesquisa. Foram aplicados 250 questionários, dos quais 189 retornaram e foram considerados completos e em condições de tratamento, o que representa cerca de $75 \%$ de aproveitamento. Os questionários foram aplicados no final do período de formação, a fim de permitir uma melhor avaliação da mesma.

\section{Os resultados}

Apresentamos a seguir a análise das estatísticas descritivas da amostra. O objetivo é caracterizar o grupo de alunos-professores por variável representativa do questionário. Em seguida, a análise das questões avaliativas permitirá a caracterização da formação nos termos propostos pelo modelo de Fabre, exposto anteriormente. 


\section{Caracterização da Amostra}

\section{Sexo}

Como pode ser visto na tabela abaixo, a constituição do grupo tem forte representação feminina, o que é corroborado por várias outras pesquisas.

Tabela 1

Distribuição da amostra por sexo

\begin{tabular}{lll}
\hline Qual é o seu sexo? & & \\
\hline Não Resposta & 1 & $0,5 \%$ \\
Masculino & 3 & $1,6 \%$ \\
Feminino & 185 & $97,9 \%$ \\
Total & 189 & $100 \%$ \\
\hline
\end{tabular}

A feminização da profissão docente é fato conhecido. A educação, na realidade, é um dos poucos setores onde as mulheres "dominam" há já algum tempo. Isso ocorre, segundo Furlani (1997, p. 76), porque,

subjacente às "escolhas" realizadas pela mulher encontra-se um processo de socialização que a leva a "gostar" de profissões "adequadas" ao seu sexo, profissões cujo exercício não lhe apresenta barreiras e nem dificulta a vida doméstica. São as "vantagens" que se oferecem às mulheres trabalhadoras para compensar desvantagens de remuneração baixa, de desprestígio social e do caráter discriminador da sociedade capitalista.

\section{Idade}

A média de idade dos indivíduos é relativamente alta (45 anos e meio), tendo a maioria idades variando entre 38 e 52 anos. Entretanto, deve-se considerar que um dos critérios para admissão no programa de formação era um mínimo de dez anos de docência e que o tempo médio de docência da amostra é de cerca de 18 anos, o que explica uma média de idade elevada. 
Tabela 2

Distribuição da amostra por idade

\begin{tabular}{lcc}
\hline \multicolumn{2}{l}{ Qual é a sua idade em anos completos? } \\
\hline Não Resposta & 2 & $1,1 \%$ \\
Menos de 36 & 18 & $9,5 \%$ \\
De 36 a 41 & 39 & $20,6 \%$ \\
De 42 a 47 & 51 & $27,0 \%$ \\
De 48 a 53 & 57 & $30,2 \%$ \\
54 e mais & 22 & $11,6 \%$ \\
Total & 189 & $100 \%$ \\
\hline
\end{tabular}

Inserção no mercado de trabalho

A maior parte dos indivíduos começou a trabalhar entre 18 e 24 anos, e cerca da metade deles teve a docência como primeira atividade.

Tabela 3a

\begin{tabular}{lcc} 
Inserção no mercado de trabalho - Idade \\
\hline \multicolumn{3}{l}{ Qual é a sua idade em anos completos? } \\
\hline Não Resposta & 2 & $1,1 \%$ \\
Menos de 36 & 18 & $9,5 \%$ \\
De 36 a 41 & 39 & $20,6 \%$ \\
De 42 a 47 & 51 & $27,0 \%$ \\
De 48 a 53 & 57 & $30,2 \%$ \\
54 e mais & 22 & $11,6 \%$ \\
Total & 189 & $100 \%$ \\
\hline
\end{tabular}

Tabela 3b

Inserção no mercado de trabalho - Profissão

\begin{tabular}{lcc}
$\begin{array}{l}\text { Você exerceu outra profissão antes de ser } \\
\text { professor(a)? }\end{array}$ \\
\hline Não Resposta \\
Sim & 1 & $0,5 \%$ \\
Não & 94 & $49,7 \%$ \\
Total & 94 & $49,7 \%$ \\
\hline
\end{tabular}




\section{Motivações para a atividade docente}

Nessa parte foram analisadas as respostas dos alunos-professores quanto às motivações para exercerem a profissão docente. Nota-se que mais da metade das respostas dizem respeito à sobrevivência familiar: os respondentes dizem trabalhar para ajudar no sustento familiar. Entretanto, também declaram gostar do que fazem.

Tabela 4

Motivação para a atividade docente

\begin{tabular}{lcc}
\hline Por que você trabalha? (Você pode assinalar mais de uma alternativa). & \\
\hline Não Resposta & 2 & $1,1 \%$ \\
Para ajudar no sustento da família & 124 & $65,6 \%$ \\
Porque gosta de trabalhar & 105 & $55,6 \%$ \\
Para ter liberdade e independência financeira & 80 & $42,3 \%$ \\
Outra razão & 24 & $12,7 \%$ \\
\hline
\end{tabular}

\section{AvaliaÇão da formação}

\section{Satisfação com a formação}

As respostas variam entre "totalmente satisfeito" e "satisfeito" o que indica que, mesmo se alguns consideram que a formação não é diretamente aplicável em sala de aula (como parece sugerir a questão sobre aplicação da formação - ver análise adiante), ela não deixa de satisfazer às expectativas dos alunos-professores.

Tabela 5

Satisfação com o programa de formação

\begin{tabular}{lcc} 
Você está satisfeito(a) com a formação que escolheu? \\
\hline Totalmente satisfeito(a) & 77 & $40,7 \%$ \\
Muito satisfeito(a) & 52 & $27,5 \%$ \\
Satisfeito(a) & 57 & $30,2 \%$ \\
Pouco satisfeito(a) & 3 & $1,6 \%$ \\
Nada satisfeito(a) & 0 & $0,0 \%$ \\
Total & 189 & $100 \%$
\end{tabular}




\section{Dificuldades encontradas na formação}

Dentre os fatores que dificultaram o processo de formação, a quase totalidade dos respondentes identifica o excesso de atividades acadêmicas, seguido da atividade doméstica, que normalmente fica sob a responsabilidade feminina. A falta de material de apoio, em particular de uma biblioteca, teve também impacto sobre o desenrolar das atividades de formação, em especial no que diz respeito ao desenvolvimento da monografia de final de curso.

Tabela 6

Fatores que dificultam a formação

\begin{tabular}{lcc}
\hline $\begin{array}{l}\text { Que fatores dificultaram estudar ou realizar suas tarefas escolares (você pode } \\
\text { assinalar mais de uma alternativa). }\end{array}$ \\
\hline Excesso de atividades & 168 & $88,9 \%$ \\
Execução de tarefas caseiras (limpeza, cozinha etc.) & 81 & $42,9 \%$ \\
Falta de material (biblioteca, computador etc.) & 52 & $27,5 \%$ \\
Falta de local apropriado para o estudo & 21 & $11,1 \%$ \\
Outros & 43 & $22,8 \%$ \\
\hline
\end{tabular}

\section{Formação e prática docente}

Quando questionados sobre a aplicação na prática docente do que foi estudado no âmbito da formação, os respondentes afirmam, na sua quase totalidade, que utilizam "muito", levando a crer numa transposição da formação em prática pedagógica.

Tabela 7

Aproveitamento da formação na prática pedagógica

\begin{tabular}{lcc}
\hline O que você aprendeu no PEC tem sido aproveitado na sua prática docente? \\
\hline Não Resposta & 3 & $1,6 \%$ \\
Muito & 167 & $88,4 \%$ \\
Um pouco & 19 & $10,1 \%$ \\
Muito pouco & 0 & $0,0 \%$ \\
Quase nada & 0 & $0,0 \%$ \\
Nada & 0 & $0,0 \%$ \\
Total & 189 & $100 \%$
\end{tabular}


Percebe-se aqui a inscrição da formação em uma problemática distinta da tradicional. De fato, é usual construir uma formação em torno da lógica epistêmica, privilegiando uma problemática de instrução, buscando a transmissão de conhecimentos aos alunos. Os resultados dessa questão parecem sugerir uma problemática de aprendizagem, construída ainda sobre a lógica epistêmica, mas buscando as aplicações práticas e a inserção do conhecimento no pólo socioprofissional.

\section{Monografia}

Os alunos-professores afirmam que o trabalho de monografia foi um momento de aprendizado, ainda que tenham tido dificuldades na sua elaboração. Quase 50\% da amostra declara ter feito o trabalho sozinho ou com ajuda de colegas, o que indica a percepção de um orientador de monografia ausente. Isso pode ser considerado uma fraqueza do programa e um ponto a ser reconsiderado em formações futuras realizadas nos mesmos moldes. Dificuldades de ordem material também foram levantadas, embora em menor porcentagem.

\section{Tabela 8}

Condições de desenvolvimento da monografia

\begin{tabular}{lcc}
\hline O seu trabalho de monografia foi feito (você pode assinalar várias opções) \\
\hline Não Resposta & 1 & $0,5 \%$ \\
Foi um momento de aprendizado & 171 & $90,5 \%$ \\
Com muitas dificuldades & 132 & $69,8 \%$ \\
Fiz sozinho(a) & 91 & $48,1 \%$ \\
Contei com a ajuda dos colegas & 89 & $47,1 \%$ \\
Com dificuldades financeiras e materiais & 44 & $23,3 \%$ \\
Em um clima angustiante & 39 & $20,6 \%$ \\
Em um ambiente prazeroso & 33 & $17,5 \%$ \\
\hline
\end{tabular}

A atividade de pesquisa, representada pelo desenvolvimento de uma monografia de final de curso, se enquadra claramente dentro da problemática da instrução, articulando os pólos epistêmico e psicológico, como já foi discutido. Entretanto, as características da monografia proposta na formação, na qual os alunos-professores trabalharam temas de seu interesse ligados a seu universo de docência, podem também inscrever a formação dentro da problemática da aprendizagem. De fato, 
isso ocorre quando a pesquisa tem um caráter finalista, sendo guiada pela resolução de um problema prático. Nesse caso, o valor formador da monografia vem de uma transferência de métodos e técnicas científicas (pólo epistêmico) para o domínio profissional.

\section{Expectativas após a formação}

Neste item os alunos-professores descrevem suas expectativas em relação à sua vida pessoal e profissional após a formação. A grande maioria acredita que utilizará seus conhecimentos e capacidade de reflexão na atividade pedagógica. Afirmam também ter mudado sua visão de mundo, ganhando segurança e autonomia em sala de aula. As preocupações de caráter mais material (futuro estável, aumento salarial) são menos ressaltadas. Finalmente, o ganho de prestígio recebeu muito pouca atenção, talvez pelo fato de que o curso superior já não é mais um fator de destaque no mundo dos professores, mas passou a fazer parte das condições mínimas para exercício da profissão.

Tabela 9

Expectativa futura

\begin{tabular}{lcr}
\hline Após a conclusão do PEC você acredita que (você pode assinalar mais de uma alternativa) \\
\hline Poderá utilizar mais sua capacidade intelectual para elaborar suas aulas & 167 & $88,4 \%$ \\
Terá mudado sua visão do mundo & 130 & $68,8 \%$ \\
Terá mais autonomia em sala de aula & 115 & $60,8 \%$ \\
Terá um futuro mais estável & 49 & $25,9 \%$ \\
Ganhará mais dinheiro & 44 & $23,3 \%$ \\
Ganhará status (prestígio) & 18 & $9,5 \%$
\end{tabular}

Apresentam-se aqui duas problemáticas, ambas centradas no pólo socioprofissional: em primeiro lugar, a associação da formação com a elaboração de aulas indica a articulação com o pólo epistêmico, dentro da problemática de aprendizagem; e em segundo lugar, a associação com a mudança na visão de mundo indica, embora de forma tênue, a articulação com o pólo psicológico, dentro da problemática de educação.

\section{Definição da formação}

Finalmente, buscou-se uma caracterização sintética da formação por parte dos alunos-professores. Para isso, várias afirmações foram 
apresentadas, buscando captar a impressão geral sobre o curso. A grande maioria indicou a aquisição de novos conhecimentos como o ponto principal da formação. Entretanto, a melhoria da prática em sala de aula, a troca de experiências e o trabalho em equipe também foram fortemente mencionados, o que mostra uma evolução da formação em relação à tradicional transmissão de conteúdos. As respostas também parecem sugerir que a formação atinge, ainda que parcialmente, a integração entre teoria e prática.

Tabela 10

Caracterização da formação

\begin{tabular}{lcc}
\hline O que é a formação PEC? (você pode assinalar mais de uma alternativa) & \\
\hline Aquisição de novos conhecimentos & 180 & $95,2 \%$ \\
Permite a melhoria da prática em sala de aula & 174 & $92,1 \%$ \\
Permite trocar informações com os colegas de profissão & 161 & $85,2 \%$ \\
Curso de qualidade & 155 & $82,0 \%$ \\
Trabalho em equipe & 155 & $82,0 \%$ \\
Atualização de conhecimentos já adquiridos & 149 & $78,8 \%$ \\
Troca com os colegas & 133 & $70,4 \%$ \\
Videoconferências e teleconferências de qualidade & 120 & $63,5 \%$ \\
Uma formação teórica & 109 & $57,7 \%$ \\
Uma formação prática & 106 & $56,1 \%$ \\
Depende do interesse pessoal do aluno & 79 & $41,8 \%$ \\
Trabalho individual & 58 & $30,7 \%$
\end{tabular}

\section{Considerações Finais}

Dentre as diversas visões possíveis sobre a formação continuada de professores - desde as de caráter mais instrumental, centradas no desenvolvimento do sistema educativo, até aquelas de caráter emancipador, que buscam o resgate identitário do professor - expusemos aqui um modelo analítico, resumido no triângulo da formação, que procura captar a lógica da construção de uma formação a partir de seus objetivos relativos ao professor. 
As três lógicas apresentadas, bem como suas possíveis articulações, buscam mapear a dinâmica da formação em termos de conteúdos transmitidos (lógica epistêmica), adaptação à atividade profissional (lógica socioprofissional) e evolução individual (lógica psicológica).

Os três pólos e problemáticas do modelo apresentado devem ser considerados tipos ideais, no sentido weberiano, na medida em que toda formação contempla, em maior ou menor grau, todas as facetas do modelo.

A presença desses três pólos na formação estudada pode ser percebida a partir da análise dos dados empíricos da pesquisa, que aborda uma situação concreta e específica de professores. Mesmo levando em consideração as limitações próprias ao método, a avaliação dos resultados obtidos mostra a utilidade do modelo analítico apresentado. Em particular, os resultados relativos às condições de desenvolvimento da monografia (Tabela 8) e as expectativas futuras dos alunos-professores (Tabela 9) indicam a presença de dinâmicas de instrução, aprendizagem e educação - no sentido definido neste trabalho - ainda que tais dinâmicas não estivessem necessariamente no desenho original da formação.

O modelo do triângulo da formação nos parece interessante tanto como possibilidade de pensar a posteriori uma formação quanto como instrumento para conceber essa formação. Ele não é, entretanto, completo e isento de críticas. Particularmente, é notável a ausência de uma análise de aspectos políticos e sociais no modelo. Ele é muito mais centrado no indivíduo e nos objetivos da formação relativos a ele. Ainda assim, a problemática da educação, que articula os pólos psicológico e socioprofissional, pode servir de base para o estudo de dispositivos de formação, aos quais está inerente uma racionalidade crítica (SILVA, 2000).

\section{Referências Bibliográficas}

ALTET, M.; FABRE, M. Logiques et problématiques d'articulation formation/ recherche dans les dispositifs de professionnalisation. Recherche et Formation. Lyon, n. 17, p. 77-92, 1994.

BOURDIEU, P.; PASSERON, J.-C. La reproduction: Eléments pour une théorie du système d'enseignement. Paris: Minuit, 1970.

CARVALHO, J. M.; SIMÕES, R. H. S. O processo de formação continuada de professores: uma construção estratégico-conceitual expressa nos periódicos. In: ANDRÉ, M. E. D. A. de (Org.). Formaşão de professores no Brasil (1990-1998). Brasília: MEC/Inep/Comped, 2002. p. 171-184. 
CASTRO, A. M. D. A. Mudanças tecnológicas e suas implicações na política de formação do professor. Ensaio: Aval. Pol. Públ. Educ. Rio de Janeiro, v. 13, n. 49, p. 469-486, out./dez. 2005.

DIAS, R. E.; LOPES, A. C. Competências na formação de professores no Brasil: o que (não) há de novo. Educação e Sociedade, Campinas, v. 24, n. 85, p. 1155-1177, dez. 2003.

DOMINGUES, I. et al. Um novo olhar sobre o conhecimento. In: DOMINGUES, I. (Org.). Conhecimento e transdisciplinaridade. Belo Horizonte:Editora UFMG/IEAT, 2001. p. 13-27.

DUARTE, V. C. Capacitação docente em Minas Gerais e São Paulo: uma análise comparativa. Cadernos de Pesquisa, v. 34, n. 121, p. 139-168, jan./abr. 2004.

FABRE, M. Penser la formation. Paris: Presses Universitaires de France, 1994.

FREITAS, H. C. L. Certificação docente e formação do educador: regulação e desprofissionalização. Educação e Sociedade, Campinas, v. 24, n. 85, p. 1095-1124, dez. 2003.

FURLANI, L. M. T. A claridade da noite: os alunos do ensino particular noturno. Tese (Doutorado em Psicologia da Educação) - Faculdade de Educação, Pontifícia Universidade Católica, São Paulo. 1997. 2 v.

GATTI, B. A. formação continuada de professores: a questão psicossocial. Cadernos de Pesquisa, n. 119, p. 191-204, jul. 2003.

HABERMAS, J. Connaissance et intérêt. Paris: Gallimard, 1976.

KUENZER, A. Z. As políticas de formação: a construção da identidade do professor sobrante. Educação e Sociedade, Campinas, v. 20, n. 68, p. 163-183, dez. 1999.

MATOS, O. C. F. Ethos e amizade: a morada do homem. In: DOMINGUES, I. (Org.). Conhecimento e transdisciplinaridade. Belo Horizonte: Editora UFMG/IEAT, 2001. p. 59-72.

PARDAL, L. A.; MARTINS, A. M. Formação contínua de professores: concepções, processos e dinâmica profissional. Psicologia da Educação, São Paulo, n. 20, p. 103-117, 2005.

PEC. Programa de Educação Continuada. Formação de professores em exercício. Programa Especial de Formação de Professores de $1^{a}$ a $4^{a}$ Séries do Ensino Fundamental. São Paulo: [s.n.], 2001. 45 p.

PIMENTEL, A. Jogo e desenvolvimento profissional: análise de uma proposta de formação continuada de professores. Tese (Doutorado em Educacão) Faculdade de Educação, Universidade de São Paulo, São Paulo, 2004.

SILVA, A. M. C. A formação contínua de professores: uma reflexão sobre as práticas e as práticas de reflexão em formação. Educação e Sociedade, Campinas, n. 72, p. 89-109, ago. 2000. 
SILVA, E. M. de P. Os caminhos da transdisciplinaridade. In: DOMINGUES, I. (Org.). Conhecimento e transdisciplinaridade. Belo Horizonte: Editora UFMG/IEAT, 2001. p. 35-43.

SIMÃO, A. M. V.; CAETANO, A. P. ; FLORES, M. A. Contextos e processos de mudança dos professores: uma proposta de modelo. Educação e Sociedade, Campinas, v. 26, n. 90, p. 173-188, jan./abr. 2005.

Recebido em: 12/07/2006 Aprovado em: 29/09/2006 